\title{
Physical activity, health-related quality of life and musculoskeletal pain among students of physiotherapy and social sciences in Eastern Croatia - Cross-sectional survey
}

\author{
Iva Sklempe Kokic ${ }^{1, A-F \oplus}$, Mateja Znika ${ }^{1, A-C, E-F \oplus}$, Vesna Brumnic ${ }^{1, A-C, E-F \oplus}$ \\ ${ }^{1}$ College of Applied Sciences "Lavoslav Ruzicka", Vukovar, Croatia \\ A - Research concept and design, B - Collection and/or assembly of data, C - Data analysis and interpretation, \\ $D$ - Writing the article, E-Critical revision of the article, F- Final approval of article
}

Sklempe Kokic I, Znika M, Brumnic V. Physical activity, health-related quality of life and musculoskeletal pain among students of physiotherapy and social sciences in Eastern Croatia - Cross-sectional survey. Ann Agric Environ Med. 2019; 26(1): 182-190. doi: 10.26444/aaem/102723

\begin{abstract}
Introduction and objective. Low levels of physical activity (PA) and sedentary lifestyle have become a major public health problem in developed countries, even among the young population. The aim of the study was to determine and compare physical activity levels, health-related quality of life (HRQoL) and the prevalence of musculoskeletal pain symptoms (MPS) among the students of Physiotherapy and Social Sciences.

Materials and method. A cross-sectional survey was performed on 517 participants and included the International Physical Activity Questionnaire - Short Form, SF-36 Health Survey, and the Nordic Musculoskeletal Questionnaire.

Results. The majority of students (61.7\%) met the criteria for the category "high" PA, and $11 \%$ respondents were in the "low" category. Male students accumulated higher levels of vigorous- and moderate-intensity PA, and scored higher in the domains of general health, vitality, and social functioning, while females scored higher in mental health $(p<0.05)$. The physical component summary score was higher for Physiotherapy students, while Social Sciences students scored higher in the mental component summary score $(p<0.05)$. The prevalence of MPS in the last year was $80.9 \%$, more among female and Physiotherapy students $(p<0.05)$. A weak association was found between MPS and lower levels of total PA, moderateintensity PA and several domains of HRQoL $(p<0.05)$.

Conclusions. Students of both disciplines reported high levels of PA, but also a high prevalence of MPS which could have affected their HRQoL which was lower than in the general population. Gender differences were found in both PA levels and HRQoL, which suggests the need for the development of gender-specific preventive programmes.
\end{abstract}

\section{Key words}

physical therapy, IPAQ, SF-36, college students, active lifestyle

\section{INTRODUCTION}

Low levels of physical activity (PA) and sedentary lifestyle have become a major public health problem contributing to the prevalence of many chronic diseases and reduced life expectancy worldwide $[1,2,3]$. Physical activity reduces the risk of heart disease, stroke, hypertension, type 2 diabetes, dementia, depression, postpartum depression, excessive weight gain, falls with injuries among the elderly, and breast and colon cancer [4]. It also improves bone and functional health and quality of life [4]. Furthermore, prolonged sedentary behaviour is independently associated with poor health outcomes [5].

Physical activity can be defined as any bodily movement produced by skeletal muscles that results in energy expenditure, while sedentary behaviour is any waking behaviour characterized by an energy expenditure of 1.5 or less metabolic equivalents of task (MET) while sitting, reclining, or lying $[6,7]$. Health-related quality of life (HRQoL) is a multi-dimensional concept including physical, mental, and social components of functioning [8]. Regular

Address for correspondence: Iva Sklempe Kokic, College of Applied Sciences "Lavoslav Ruzicka" in Vukovar

e-mail: ivasklempe@yahoo.com

Received: 14.11.2018; accepted: 09.01.2019; first published: 01.02.2019
PA enhances HRQoL and contributes to perceived well-being in the general adult population [9], but the dose-response relationship between PA and HRQoL is still controversial. Lower levels of PA are associated with lower HRQoL [10]. However, higher levels of PA have been associated with both lower [11] and higher [12] HRQoL.

Current recommendations state that the adult population should engage in aerobic PA of at least moderate-intensity for a minimum of 150 minutes/week, or 75 minutes/week of vigorous-intensity, or an equivalent combination, e.g. 500 to 1,000 MET-minutes/week of moderate-to-vigorous PA $[2,4]$. Increasing levels of moderate- and vigorous-intensity aerobic PA to 300 and 150 minutes/week, respectively, provides additional health benefits. However, worldwide, 1 in 4 adults do not currently meet these recommendations [13] and $30.5 \%$ of the Croatian adult population is considered physically inactive [14]. Healthcare students, especially physiotherapy students, are expected to have more knowledge about the benefits of PA than students of other disciplines. Physiotherapists, physiotherapy assistants, and students of physiotherapy reported higher levels of PA than other healthcare professionals and the general population in the USA [15].

Musculoskeletal disorders (MSD) are dysfunctions or injuries that affect musculoskeletal structures, including 
muscles, bones, joints, tendons, nerves and ligaments [16]. The most common manifestation of MSDs are musculoskeletal pain symptoms (MPS) [17]. Neck, shoulder, and back pain are common among college students, including physiotherapy students $[18,19]$. A strong association has been reported between the educational posture of "sitting looking down" and one-month prevalence of low back pain among physiotherapy students [19]. Engaging in exercise and sports was not associated with any MPS in allied health students $[19,20]$. However, moderate-intensity physical activity was associated with less neck and shoulder pain and low back pain in Norwegian adolescents [21]. Musculoskeletal disorders have a deleterious effect on HRQoL among young adults [22]. However, there is still limited data related to PA of different intensities, HRQoL, and the prevalence of musculoskeletal symptoms in the university student population.

\section{OBJECTIVE}

The aim of this study was to determine the levels of different intensities of PA, HRQoL, and the prevalence of musculoskeletal symptoms among the students of Physiotherapy and Social Sciences in Eastern Croatia. A secondary aim was to explore the relationship between the levels of different intensities of PA, HRQoL, and the prevalence of musculoskeletal symptoms in this population. Data regarding students' level of PA and possible interactions between PA, HRQoL and musculoskeletal symptoms are still insufficient, which could interfere with the successful planning and implementation of strategies for the promotion of active lifestyle. It was hypothesized that Physiotherapy students will accumulate higher levels of PA and that those with higher levels of PA at moderate and vigorous intensities will report a higher HRQoL and a lower prevalence of musculoskeletal symptoms.

\section{MATERIALS AND METHOD}

A cross-sectional study using a self-administered questionnaire was conducted. The target population were the students of The College of Applied Sciences "Lavoslav Ruzicka" in Vukovar, Croatia, enrolled in the academic year 2017-2018. This higher education institution offers 3-year Bachelor's study programmes in Physiotherapy and Social Sciences (Public Administration and Commerce) and a Master study programme in Physiotherapy. There were no exclusion criteria.

The respondents were invited to participate during their classes. Participation was voluntary and anonymous, and each one had given written consent. Data were collected between November - December 2017 using paper-based survey questionnaires which included demographic information and self-reported PA levels, HRQoL and presence of MPS. The questionnaire was pretested on a sample of 20 students before being distributed to the participants to ensure a good understanding of the questions.

Demographic information collected in the questionnaire included data on age, gender, body height and body mass, the course of the study, and year of study. Body mass index (BMI) was calculated according to standard equation from self-reports of body height and body mass, and students having a BMI $>25$ were classified as overweight. Additionaly, students were asked how much they could agree with the statement "my level of PA is adequate" on a Likert-type scale of 1-5 where 1 represented the answer "strongly disagree", and 5 represented the answer "strongly agree".

Physical activity was assessed using the International Physical Activity Questionnaire - Short Form (IPAQ-SF) (Croatian version) [23] which is publicly available, and no permissions are required to use it. This questionnaire was selected because of its use worldwide in the assessment of PA which allows for the comparison of the results. The questionnaire aimed to identify the frequency and duration of walking, moderate-intensity PA, vigorous-intensity PA, as well as the time spent sitting for the previous 7 days. Data were processed according to established guidelines [24] and presented as MET-minutes per week. One MET is the rate of energy expenditure while sitting at rest, which, for most people, approximates an oxygen uptake of 3.5 milliliters per kilogram per minute [4]. According to the IPAQ scoring protocol, MET-minutes per week of specific activity are computed by multiplying the MET value of a particular activity with minutes spent doing that particular activity. The following values of the intensity of PA were used in the analysis: walking $=3.3 \mathrm{MET}$, moderate-intensity $\mathrm{PA}=4.0$ $\mathrm{MET}$, vigorous-intensity $\mathrm{PA}=8.0 \mathrm{MET}$. The questionnaire also assesses the average time spent sitting per day.

Students were classified into 3 different categories of physical activity level: low (1), moderate (2) and high (3). Participants who had vigorous-intensity PA on at least 3 days, achieving a minimum total PA of at least 1,500 METminutes per week, or had 7 days a week of any combination of walking, moderate-, or vigorous-intensity PA, achieving a minimum total PA of at least 3,000 MET-minutes per week, were classified into category 3 . Those who had 3 or more days of vigorous-intensity PA of at least 20 minutes per day, or 5 or more days of moderate-intensity activity and/or walking of at least 30 minutes per day, or 5 or more days of any combination of walking, moderate- or vigorous-intensity PA, achieving a minimum total PA of at least 600 MET-minutes per week were classified in category 2. Participants who did not meet the criteria for category 2 or 3 were classified in category 1 .

Participant HRQoL was assessed by the SF-36 Health Survey (SF-36) (Croatian version), which consists of 36 items grouped into 8 main domains of health [25, 26, 27]. The questionnaire was used according to its terms and conditions. Each category was scored on a scale of $0-100$, were 0 represents the worst overall health status and 100 the best health status. The physical health component consists of physical functioning, role funcioning/physical, bodily pain, and general health. Mental health consists of vitality, social functioning, role functioning/emotional, and mental health. The 8 scales are then combined into 2 summary measures: physical component summary (PCS) and mental component summary (MCS) scores. These 2 distinct summary components were aggregated using the Croatian reference population [28]. Scoring and calculation of scales were performed by using the survey's manual [ 26 , 29]. This questionnare was selected for the current tudy because of its acceptable psychometric characteristics tested on a representative sample of Croatian adult population [28]. Also, it is widely used in the assessment of HRQoL and allows for comparison of the results. 
Musculoskeletal pain symptoms were assessed using the Nordic Musculoskeletal Questionnaire [30]. The Nordic Musculoskeletal Questionnare can be used for the screening of musculoskeletal problems and allows for the comparison of MPS in different body regions in studies with large number of participants. The questionnaire is available in the public domain, license free. It was translated into Croatian following accepted standards and using the back-translation technique to ensure linguistic validity. This is a valid assessment tool of MPS in the neck, shoulders, elbows, wrist and hands, the upper and lower back, hips, knees, ankles and feet. The respondents indicated whether they have had MPS in the past 12 months and the past week. They also reported if they had daily life activity limitations due to their MPS. For the purpose of this study, only the data regarding the MPS in the past 12 months was analysed.

Statistical Analysis. Statistical analyses were performed using SPSS 19.0 (IBM, Armonk, NY, USA). The level of significance was set at $\mathrm{p}<0.05$. The Shapiro-Wilk test was performed to check for normality of data and showed nonnormal distribution for all variables. Continuous variables were presented as medians and inter-quartile ranges. Categorical variables were summarized by frequencies and percentages. Reliability and the internal consistency of the SF-36 questionnaire were assessed by Cronbach's alpha, and convergent and discriminant validity were checked using Spearman's correlation $\left(\mathrm{r}_{\mathrm{s}}\right)$.

The Chi-square test was used to test for differences between gender, course of study and the 3 categories of PA. Mann Whitney U test and Kruskal-Wallis $\mathrm{H}$ test were used to test for differences between gender, course of study and categories of PA for continuous variables. Spearman's correlation $\left(\mathrm{r}_{\mathrm{s}}\right)$ analyses were performed to examine the association across different intensities of PA, scores of SF-36, and continuous variables of demographic characteristics. Point-biserial correlation coefficient $\left(\mathrm{r}_{\mathrm{pbi}}\right)$ was calculated to assess for association between MPS in general, different intensities of PA, and scores of SF-36.
A series of hierarchical multiple linear regression analyses were conducted to determine the impact of PA levels and MPS on HRQoL. In these models, socio-demographic data (age, gender, course of the study and BMI) were entered in Step 1 and PA levels (vigorous-intensity PA, moderate-intensity PA, walking, total PA and sedentary behaviour), as well as MPS (in general in the past year, and in general in the past year preventing activity) were entered in Step 2. Tolerance and variance inflation factor (VIF) were used to check for multicollinearity.

\section{RESULTS}

From a total 685 students invited to participate in the study, 517 responded to the survey (75.5\% response rate). Table 1 summarizes participants' characteristics for the total sample, by gender, and by course of the study. $23 \%$ of the students were classified as overweight. Male students had a higher BMI than female $(\mathrm{p}<0.05)$, but both subgroups were within normal limits. However, a greater percentage of male students (39.6\% vs. $13.9 \% ; \mathrm{p}<0.05)$ and Social Sciences students $(29 \%$ vs. $19.4 \% ; \mathrm{p}<0.05)$ were found to be overweight.

Table 2 shows respondents' levels of PA by intensity and sedentary behaviour for the total sample, by gender, and by the course of the study. The male students believed that they reached adequate levels of PA to a greater extent than the female students $(4 \pm 2$ vs. $3 \pm 2 ; \mathrm{p}<0.05)$. Indeed, the male respondents accumulated higher levels of vigorous-intensity PA in comparison to the female respondents $(2400 \pm 3120$ vs. $480 \pm 1920 \mathrm{MET}-\mathrm{min} /$ week; $\mathrm{p}<0.05)$. They also reported higher levels of moderate-intensity PA and total levels of PA. There were no differences between students of Physiotherapy and Social Sciences in their PA levels.

Regarding the categories of physical activity, the majority of students (61.7\%) met the criteria for the category "high", and only $11 \%$ respondents were in the category "low". However, differences were found by gender $(\mathrm{p}<0.05)$. Only $5.9 \%$ of male respondents were in the category "low", compared to $13.9 \%$

Table 1. Participants' characteristics

\begin{tabular}{|c|c|c|c|c|c|}
\hline & $\begin{array}{l}\text { All participants } \\
\qquad(\mathrm{N}=517)\end{array}$ & $\begin{array}{l}\text { Females } \\
(\mathrm{N}=330)\end{array}$ & $\begin{array}{c}\text { Males } \\
(\mathrm{N}=187)\end{array}$ & $\begin{array}{l}\text { Physiotherapy students } \\
\qquad(\mathrm{N}=310)\end{array}$ & $\begin{array}{l}\text { Social sciences students } \\
\qquad(N=207)\end{array}$ \\
\hline \multicolumn{6}{|c|}{ median \pm IQR or $\mathrm{N}(\%)$} \\
\hline \multicolumn{6}{|l|}{ Gender } \\
\hline Female & $330(63.8)$ & - & - & $208(67.2)$ & $122(58.9)$ \\
\hline Male & $187(36.2)$ & - & - & $102(32.9)$ & $85(41.1)$ \\
\hline $\mathrm{BMI}\left(\mathrm{kg} / \mathrm{m}^{2}\right)$ & $22.3 \pm 4.3$ & $21.5 \pm 3.1$ & $24.5 \pm 4.1$ & $22 \pm 4$ & $22.9 \pm 5.1$ \\
\hline Overweight & $120(23.2)$ & $46(13.9)$ & $74(39.6)$ & $60(19.4)$ & $60(29)$ \\
\hline \multicolumn{6}{|l|}{ Course of study } \\
\hline Physiotherapy & $310(60)$ & $208(63)$ & $102((54.5)$ & - & - \\
\hline Social sciences & $207(40)$ & $122(37)$ & $85(45.5)$ & - & - \\
\hline \multicolumn{6}{|l|}{ Year of study } \\
\hline $1 \mathrm{st}$ & $167(32.3)$ & $105(31.8)$ & $62(33.2)$ & 105(33.9) & $62(30)$ \\
\hline 2nd & $160(30.9)$ & $91(27.6)$ & $69(36.9)$ & $85(27.4)$ & $75(36.2)$ \\
\hline $3 r d$ & $146(28.2)$ & $103(31.2)$ & $43(23)$ & $76(24.5)$ & $70(33.8)$ \\
\hline 4th & $15(2.9)$ & $13(3.9)$ & $2(1.1)$ & $15(4.8)$ & $0(0)$ \\
\hline 5 th & $29(5.6)$ & $18(5.5)$ & $11(5.9)$ & 29(9.4) & $0(0)$ \\
\hline
\end{tabular}

$\mathrm{N}$ - sample; IQR - interquartile range; $\mathrm{BMI}$ - body mass index 
Table 2. Physical activity levels and sedentary behaviour

\begin{tabular}{|c|c|c|c|c|c|c|c|}
\hline & \multirow[b]{2}{*}{$\begin{array}{l}\text { All participants } \\
\qquad(\mathrm{N}=517)\end{array}$} & \multicolumn{2}{|c|}{ Gender } & \multirow[b]{2}{*}{$p$} & \multicolumn{2}{|c|}{ Course of study } & \multirow[b]{2}{*}{$\mathrm{p}$} \\
\hline & & $\begin{array}{l}\text { Females } \\
(\mathrm{N}=330)\end{array}$ & $\begin{array}{c}\text { Males } \\
(\mathrm{N}=187)\end{array}$ & & $\begin{array}{l}\text { Physiotherapy } \\
\text { students } \\
(\mathrm{N}=310)\end{array}$ & $\begin{array}{c}\text { Social sciences } \\
\text { students } \\
(N=207)\end{array}$ & \\
\hline \multicolumn{8}{|c|}{ median \pm IQR or $\mathrm{N}(\%)$} \\
\hline Attitude towards reaching appropriate levels of PA (1-5) & $3 \pm 2$ & $3 \pm 2$ & $4 \pm 2$ & $<0.001^{\mathrm{b} *}$ & $3 \pm 2$ & $3 \pm 2$ & $0.579^{\mathrm{b}}$ \\
\hline Vigorous-intensity PA (MET-min/week) & $960 \pm 2880$ & $480 \pm 1920$ & $2,400 \pm 3,120$ & $<0.001^{\mathrm{b} *}$ & $960 \pm 2880$ & $1,440 \pm 2,640$ & $0.072^{b}$ \\
\hline Moderate-intensity PA (MET-min/week) & $720 \pm 1330$ & $480 \pm 1140$ & $960 \pm 1560$ & $<0.001^{\mathrm{b} *}$ & $720 \pm 1,280$ & $600 \pm 1560$ & $0.949^{b}$ \\
\hline Walking (MET-min/week) & $1,188 \pm 2,326.5$ & $1,188 \pm 2,376$ & $1,237.5 \pm 2,310$ & $0.978^{\mathrm{b}}$ & $1,188 \pm 2,310$ & $1,386 \pm 2,376$ & $0.891^{\mathrm{b}}$ \\
\hline Total PA (MET-min/week) & $3,759 \pm 4,341$ & $2,974.5 \pm 4,082.3$ & $5,118 \pm 4,502$ & $<0.001^{\mathrm{b} *}$ & $3,483 \pm 4,326$ & $4,062 \pm 4,373$ & $0.320^{\mathrm{b}}$ \\
\hline Sedentary behaviour (h/day) & $5 \pm 3.5$ & $5 \pm 3.2$ & $5 \pm 3.5$ & $0.570^{\mathrm{b}}$ & $5 \pm 3.2$ & $5.5 \pm 4$ & $0.001^{\mathrm{b}}$ \\
\hline \multicolumn{8}{|l|}{ PA category } \\
\hline Low & $57(11)$ & $46(13.9)$ & $11(5.9)$ & \multirow{2}{*}{$<0.001^{a *}$} & $33(10.6)$ & $24(11.6)$ & \multirow{2}{*}{$0,860^{\circ}$} \\
\hline High & $3,19(61.7)$ & $177(53.6)$ & $142(75.9)$ & & 190(61.3) & $129(62.3)$ & \\
\hline
\end{tabular}

$\mathrm{N}$ - sample; IQR - interquartile range; PA - physical activity; MET - metabolic equivalent

${ }^{\mathrm{a}}$ Chi-square Test; ${ }^{\mathrm{b}}$ Mann Whitney U test; ${ }^{*}$ statistically significant

of female respondents. Furthermore, $75.9 \%$ of male students met the criteria for the category "high", compared to $53.6 \%$ of female students. Students spent, on average, $5 \pm 3.5$ hours/day sitting, and the Social Sciences students remained longer in the sitting position per day than the Physiotherapy students $(5.5 \pm 4 h$ vs. $5 \pm 3.2 \mathrm{~h} ; \mathrm{p}<0.05)$.

Weak positive relationships were found between BMI and vigorous-intensity $\mathrm{PA}(\mathrm{p}<0.05 ; \mathrm{r}=0.153)$, moderate-intensity PA $\left(p<0.05 ; r_{s}=0.09\right)$ and total PA $\left(p<0.05 ; r_{s}=0.166\right)$. The level of agreement with the statement "my level of PA is adequate" positively correlated with vigorous-intensity PA $\left(\mathrm{p}<0.05 ; \mathrm{r}_{\mathrm{s}}=0.5\right)$, moderate-intensity $\mathrm{PA}\left(\mathrm{p}<0.05 ; \mathrm{r}_{\mathrm{s}}=0.327\right)$, walking $\left(\mathrm{p}<0.05 ; \mathrm{r}_{\mathrm{s}}=0.12\right)$, and total $\mathrm{PA}\left(\mathrm{p}<0.05 ; \mathrm{r}_{\mathrm{s}}=0.422\right)$, and negatively correlated with the time spent sitting $(\mathrm{p}<0.05$; $\left.r_{s}=-0.206\right)$.

The results of SF-36 are presented in Table 3 for the total sample, by gender, by course of study, and by categories of physical activity. The psychometric evaluation of the questionnare showed acceptable results (Tab. 4). The students scored the highest in the domains of role functioning/physical and role functioning/emotional, while the lowest scores were in the domains of mental health and vitality. Scores for the domains of physical functioning and bodily pain were $90 \pm 50$ and $70.5 \pm 29$, respectively, without significant differences regarding the gender, course of study and category of PA.

Male students scored higher in the domains of general health, vitality, and social functioning. The only domain where female students scored higher was mental health. The Physiotherapy students scored higher in the domain of physical functioning. The physical component summary score was higher for the students of Physiotherapy, while the MCS score was higher for the students of Social Sciences. Regarding the differences between specific categories of $\mathrm{PA}$, post hoc analysis revealed differences in favour of the subgroup "high" vs. "low" in the domains of general health and vitality.

A weak positive relationship was found between students' $\mathrm{BMI}$ and the domains of role functioning/physical $(\mathrm{p}<0.05$; $\left.\mathrm{r}_{\mathrm{s}}=0.117\right)$, role functioning/emotional $\left(\mathrm{p}<0.05 ; \mathrm{r}_{\mathrm{s}}=0.142\right)$, and vitality $\left(\mathrm{p}<0.05 ; \mathrm{r}_{\mathrm{s}}=0.092\right)$. The level of agreement with the

Table 3. Health-related quality of life (36-Item Short Form Survey)

\begin{tabular}{|c|c|c|c|c|c|c|c|c|c|c|c|}
\hline & \multirow{2}{*}{$\begin{array}{c}\text { All } \\
\text { participants } \\
(\mathrm{N}=517)\end{array}$} & \multicolumn{2}{|c|}{ Gender } & \multirow[b]{2}{*}{$\mathrm{p}$} & \multicolumn{2}{|c|}{ Course of study } & \multirow[b]{2}{*}{$\mathrm{p}$} & \multicolumn{3}{|c|}{ Category of PA } & \multirow[b]{2}{*}{$\mathrm{p}$} \\
\hline & & $\begin{array}{l}\text { Females } \\
(\mathrm{N}=330)\end{array}$ & $\begin{array}{c}\text { Males } \\
(\mathrm{N}=187)\end{array}$ & & $\begin{array}{l}\text { Physiotherapy } \\
\text { students } \\
(\mathrm{N}=310)\end{array}$ & $\begin{array}{l}\text { Social sciences } \\
\text { students } \\
(\mathrm{N}=207)\end{array}$ & & $\begin{array}{c}\text { Low } \\
(N=57)\end{array}$ & $\begin{array}{c}\text { Moderate } \\
(\mathrm{N}=141)\end{array}$ & $\begin{array}{c}\text { High } \\
(\mathrm{N}=319)\end{array}$ & \\
\hline \multicolumn{12}{|c|}{ median \pm IQR } \\
\hline Physical functioning & $90 \pm 50$ & $90 \pm 45$ & $90 \pm 65$ & $0.823^{b}$ & $95 \pm 25$ & $80 \pm 60$ & $<0.001^{\mathrm{b} *}$ & $85 \pm 35$ & $90 \pm 45$ & $90 \pm 60$ & $0.199^{c}$ \\
\hline Role functioning/physical & $100 \pm 37.5$ & $100 \pm 50$ & $100 \pm 25$ & $0.101^{b}$ & $100 \pm 25$ & $100 \pm 50$ & $0.309^{b}$ & $100 \pm 25$ & $100 \pm 25$ & $100 \pm 50$ & $0.579^{c}$ \\
\hline Bodily pain & $70.5 \pm 29$ & $70.5 \pm 29$ & $70.5 \pm 46$ & $0.365^{b}$ & $70.5 \pm 29$ & $70.5 \pm 46$ & $0.707^{b}$ & $70.5 \pm 29$ & $70.5 \pm 50$ & $70.5 \pm 29$ & $0.868^{c}$ \\
\hline General health & $70 \pm 25$ & $65 \pm 20$ & $70 \pm 20$ & $0.007^{b *}$ & $70 \pm 25$ & $70 \pm 25$ & $0.753^{\mathrm{b}}$ & $65 \pm 22.5$ & $70 \pm 25$ & $70 \pm 20$ & $0.013^{\mathrm{c} *}$ \\
\hline Vitality & $62.5 \pm 28.1$ & $62.5 \pm 31.2$ & $62.5 \pm 25$ & $0.018^{\mathrm{b*}}$ & $62.5 \pm 31.2$ & $62.5 \pm 25$ & $0.780^{\mathrm{b}}$ & $50 \pm 31.3$ & $56.3 \pm 31.2$ & $62.5 \pm 25$ & $<0.001^{c *}$ \\
\hline Social functioning & $75 \pm 42$ & $70.5 \pm 33.5$ & $83 \pm 33.5$ & $0.002^{\mathrm{b*}}$ & $83 \pm 42$ & $70.5 \pm 29.5$ & $0.399^{b}$ & $75 \pm 31.5$ & $70.5 \pm 42$ & $83 \pm 42$ & $0.441^{c}$ \\
\hline Role functioning/emotional & $100 \pm 33.3$ & $100 \pm 66.7$ & $100 \pm 33.3$ & $0.007^{b}$ & $100 \pm 33.3$ & $100 \pm 33.3$ & $0.559^{b}$ & $100 \pm 33.3$ & $100 \pm 33.3$ & $100 \pm 33.3$ & $0.795^{c}$ \\
\hline Mental health & $50 \pm 25$ & $50 \pm 20$ & $50 \pm 25$ & $0.019^{b *}$ & $50 \pm 20$ & $50 \pm 30$ & $0.411^{b}$ & $55 \pm 20$ & $50 \pm 25$ & $50 \pm 25$ & $0.023^{\text {c* }}$ \\
\hline PCS & $55.7 \pm 11$ & $55.2 \pm 10.9$ & $56.3 \pm 10.7$ & $0.353^{b}$ & $57.2 \pm 10.5$ & $53.4 \pm 11.9$ & $<0.001^{\mathrm{b} *}$ & $54.9 \pm 9.9$ & $55.6 \pm 8.8$ & $56 \pm 12.1$ & $0.592^{c}$ \\
\hline MCS & $48.3 \pm 8.9$ & $48 \pm 9.1$ & $49 \pm 0.4$ & $0.104^{b}$ & $47.7 \pm 8.5$ & $49.6 \pm 9.1$ & $0.005^{\mathrm{b*}}$ & $49 \pm 8.6$ & $47.8 \pm 8.2$ & $48.9 \pm 9.5$ & $0.525^{c}$ \\
\hline
\end{tabular}

$\mathrm{N}$ - sample; IQR - interquartile range; PCS - physical component summary; MCS - mental component summary

${ }^{\mathrm{b}}$ Mann Whitney U test; ' Kruskal-Wallis test; ${ }^{*}$ statistically significant 
Table 4. Validity and reliability for SF-36 questionnaire

\begin{tabular}{lcccc}
\hline & $\begin{array}{c}\text { Number of } \\
\text { items per } \\
\text { scale }\end{array}$ & $\begin{array}{c}\text { Convergent } \\
\text { validity } \\
\text { (range of } \\
\text { correlation) }\end{array}$ & $\begin{array}{c}\text { Discriminant } \\
\text { validity } \\
\text { (range of } \\
\text { correlation) }\end{array}$ & $\begin{array}{c}\text { Reliability } \\
\text { (Cronbach's a) }\end{array}$ \\
\hline Physical functioning & 10 & $0.65-0.82$ & $0.01-0.27$ & 0.95 \\
\hline Role physical & 4 & $0.69-0.81$ & $0.18-0.43$ & 0.76 \\
\hline Bodily pain & 2 & $0.84-0.97$ & $0.12-0.41$ & 0.82 \\
\hline General health & 5 & $0.57-0.76$ & $0.01-0.41$ & 0.74 \\
\hline Vitality & 4 & $0.59-0.76$ & $0.01-0.63$ & 0.80 \\
\hline Social functioning & 2 & $0.79-0.91$ & $0.09-0.48$ & 0.70 \\
\hline Role emotional & 3 & $0.72-0.86$ & $0.01-0.42$ & 0.76 \\
\hline Mental health & 5 & $0.67-0.75$ & $0.01-0.57$ & 0.79 \\
\hline
\end{tabular}

statement "my level of PA is adequate" positively correlated with the domains of role functioning/emotional ( $\mathrm{p}<0.05$; $\left.r_{s}=0.089\right)$, vitality $\left(p<0.05 ; r_{s}=0.256\right)$, social functioning $\left(\mathrm{p}<0.05 ; \mathrm{r}_{\mathrm{s}}=0.110\right)$, general health $\left(\mathrm{p}<0.05 ; \mathrm{r}_{\mathrm{s}}=0.266\right)$, PCS $\left(\mathrm{p}<0.05 ; \mathrm{r}_{\mathrm{s}}=0.089\right)$, and MCS $\left(\mathrm{p}<0.05 ; \mathrm{r}_{\mathrm{s}}=0.129\right)$. There was a positive relationship between vitality and vigorousintensity PA $\left(\mathrm{p}<0.05 ; \mathrm{r}_{\mathrm{s}}=0.161\right)$, moderate-intensity PA $\left(\mathrm{p}<0.05 ; \mathrm{r}_{\mathrm{s}}=0.097\right)$, total PA $\left(\mathrm{p}<0.05 ; \mathrm{r}_{\mathrm{s}}=0.139\right)$, and a negative relationship between vitality and the time spent sitting $\left(\mathrm{p}<0.05 ; \mathrm{r}_{\mathrm{s}}=-0.113\right)$.

The domain of mental health was negatively associated with vigorous-intensity PA $\left(\mathrm{p}<0.05 ; \mathrm{r}_{\mathrm{s}}=-0.101\right)$, moderateintensity PA $\left(\mathrm{p}<0.05 ; \mathrm{r}_{\mathrm{s}}=-0.103\right)$, and total PA $(\mathrm{p}<0.05$; $\left.r_{s}=-0.125\right)$. Social functioning negatively correlated with the time spent sitting $\left(\mathrm{p}<0.05 ; \mathrm{r}_{\mathrm{s}}=-0.096\right)$. General health was in a positive relationship with vigorous-intensity PA $(\mathrm{p}<0.05$; $\left.\mathrm{r}_{\mathrm{s}}=0.121\right)$, moderate-intensity PA $\left(\mathrm{p}<0.05 ; \mathrm{r}_{\mathrm{s}}=0.103\right)$, total PA $\left(p<0.05 ; r_{s}=0.115\right)$, and in a negative relationship with the time spent sitting $\left(\mathrm{p}<0.05 ; \mathrm{r}_{\mathrm{s}}=-0.120\right)$. There was a weak negative relationship between role functioning/emotional and walking $\left(\mathrm{p}<0.05 ; \mathrm{r}_{\mathrm{s}}=-0.094\right)$. The mental component summary score negatively correlated with the time spent sitting $\left(\mathrm{p}<0.05 ; \mathrm{r}_{\mathrm{s}}=-0.120\right)$.
Eighty-one percent of the students reported MPS in different regions of body in the last year, with a higher prevalence among females $(87.3 \%$ vs. $69.5 \%$; $\mathrm{p}<0.05)$. Female students also reported higher prevalence of MPS in the neck (53.9\% vs. $34.2 \%$; $<<0.05)$, shoulders (33.9\% vs. $24.1 \%$; $<<0.05)$, the upper back ( $46.1 \%$ vs. $24.6 \%$; $<<0.05)$, and the lower back (61.2\% vs. $46 \%$; $\mathrm{p}<0.05)$. The Physiotherapy students reported higher percentage of MPS in general in the last 12 months than the Social Sciences students (86.8\% vs. $72 \%$; $<0.05)$, along with a higher percentage of MPS in the neck (51.9\% vs. $39.1 \%$; p < 0.05$)$, lower back ( $60.6 \%$ vs. $48.3 \%$; $\mathrm{p}<0.05)$, and knees (36.1\% vs. $26.1 \%$; $\mathrm{p}<0.05)$. Musculoskeletal pain symptoms prevented activities for $33.8 \%$ of the total sample in the last 12 months, with a higher percentage among Physiotherapy students $(37.1 \%$ vs. $29 \%$; p<0.05). Female respondents reported a higher percentage of MPS in the lower back which prevented their daily activities during the past 12 months $(22.1 \%$ vs. $15 \%$; $\mathrm{p}<0.05)$.

The presence of MPS in the previous year was associated with lower levels of moderate-intensity PA $(\mathrm{p}<0.05$; $\left.r_{p b i}=-0.106\right)$, total PA $\left(p<0.05 ; r_{p b i}=-0.106\right)$, and lower scores in the domains of vitality $\left(\mathrm{p}<0.05 ; \mathrm{r}_{\mathrm{pbi}}=-0.11\right)$, bodily pain $\left(\mathrm{p}<0.05 ; \mathrm{r}_{\mathrm{pbi}}=-0.138\right)$, and MCS $\left(\mathrm{p}<0.05 ; \mathrm{r}_{\mathrm{pbi}}=-0.095\right)$. Likewise, MPS in the last year which prevented activities was associated with lower scores in the domains of role functioning/physical $\left(\mathrm{p}<0.05 ; \mathrm{r}_{\mathrm{pbi}}=-0.243\right)$, role functioning/emotional $(\mathrm{p}<0.05$; $\left.\mathrm{r}_{\mathrm{pbi}}=-0.186\right)$, vitality $\left(\mathrm{p}<0.05 ; \mathrm{r}_{\mathrm{pbi}}=-0.152\right)$, social functioning $\left(\mathrm{p}<0.05 ; \mathrm{r}_{\mathrm{pbi}}=-0.162\right)$, bodily pain $\left(\mathrm{p}<0.05 ; \mathrm{r}_{\mathrm{pbi}}=-0.314\right)$, general health $\left(\mathrm{p}<0.05 ; \mathrm{r}_{\mathrm{pbi}}=-0.213\right)$, PCS $\left(\mathrm{p}<0.05 ; \mathrm{r}_{\mathrm{pbi}}=-0.213\right)$, and $\operatorname{MCS}\left(\mathrm{p}<0.05 ; \mathrm{r}_{\mathrm{pbi}}=-0.112\right)$. However, a relationship we found between MPS in the last year preventing activities and higher levels of vigorous-intensity PA $\left(\mathrm{p}<0.05 ; \mathrm{r}_{\mathrm{pbi}}=0.128\right)$ and total levels of PA $\left(\mathrm{p}<0.05 ; \mathrm{r}_{\mathrm{pbi}}=0.098\right)$. Furthermore, no relationships were found between the domain of physical functioning and physical activity, sedentary behaviour or the presence of MPS in the previous year.

Multiple regression analysis revealed that sociodemographic characteristics accounted for $22 \%$ of the variation in MCS scores, while sedentary behaviour added an

Table 5. Multiple regression analysis examining the contribution of sociodemographic variables, physical activity and MPS to PCS and MCS scores

\begin{tabular}{|c|c|c|c|c|c|c|c|c|c|c|c|}
\hline \multicolumn{4}{|c|}{ Dependant variable: PCS scores } & \multicolumn{8}{|c|}{ Dependant variable: MCS scores } \\
\hline & $b$ & SE b & B & & $b$ & SE b & $\beta$ & & $b$ & SE b & $\beta$ \\
\hline Step 1 & & & & Step 1 & & & & Step 1 & & & \\
\hline Constant & 56.59 & 3.32 & & Constant & 45.95 & 3.39 & & Constant & 45.92 & 3.39 & \\
\hline Age & 0.21 & 0.08 & $0.12^{*}$ & Age & -0.05 & 0.78 & -0.03 & Age & -0.05 & 0.08 & -0.03 \\
\hline Gender & -0.82 & 0.73 & -0.05 & Gender & -1.08 & 0.74 & -0.07 & Gender & -1.08 & 0.74 & -0.07 \\
\hline Course of study & -3.08 & 0.68 & $-0.20^{* * *}$ & Course of study & 1.74 & 0.69 & $0.11^{*}$ & Course of study & 1.74 & 0.69 & $0.11^{*}$ \\
\hline Step 2 & & & & Step 2 & & & & Step 2 & & & \\
\hline Constant & 62.37 & 3.43 & & Constant & 48.76 & 3.58 & & Constant & 47.14 & 3.37 & \\
\hline Age & 0.16 & 0.08 & $0.10^{*}$ & Age & -0.07 & 0.08 & -0.04 & Age & -0.04 & 0.08 & -0.02 \\
\hline Gender & -0.75 & 0.71 & -0.05 & Gender & -1.05 & 0.74 & -0.07 & Gender & -0.92 & 0.74 & -0.06 \\
\hline Course of study & -3.25 & 0.66 & $-0.22^{* * *}$ & Course of study & 1.66 & 0.70 & $0.11^{*}$ & Course of study & 2.06 & 0.69 & $0.13^{* *}$ \\
\hline $\begin{array}{l}\text { MPS (preventing activity } \\
\text { in the past year) }\end{array}$ & -3.40 & 0.67 & $-0.22^{* * *}$ & $\begin{array}{l}\text { MPS (preventing activity } \\
\text { in the past year) }\end{array}$ & -1.65 & 0.70 & $-0.10^{* *}$ & $\begin{array}{l}\text { PA (Sedentary } \\
\text { behaviour) }\end{array}$ & -0.46 & 0.13 & $-0.16^{* * *}$ \\
\hline
\end{tabular}

$R^{2}=0.45$ for Step 1: $\Delta R^{2}=0.46$ for Step $2(p<0.05)$

$R^{2}=0.22$ for Step $1: \Delta R^{2}=0.11$ for Step $2(p<0.05)$

$\mathrm{R}^{2}=0.22$ for Step $1: \Delta \mathrm{R}^{2}=0.24$ for Step $2(\mathrm{p}<0.05)$

$p<0.05 ; * * 0<0.01 ; * * * 0<0.001 ; P C S$ - physical component summary; MCS - mental component summary; SE - standard error; b - unstandardized coefficient;

$\beta$ - standardized coefficient; BMI - body mass index; MPS - musculoskeletal pain symptom; PA - physical activity 
extra $24 \%$ (Tab. 5). There was a positive association between studying social sciences and MCS scores, and negative association between sitting time and MCS scores. Studying physiotherapy was positively associated with PCS scores. Socio-demographic characteristics accounted for $45 \%$ of the variation in PCS scores, while MPS in general in the past year preventing activities added an extra $46 \%$ (Tab. 5). Physical acitivity variables did not contribute significantly to the model regarding the PCS scores. MPS preventing activity in the past year were negatively associated with both PCS and MCS scores $(\mathrm{p}<0.05)$.

\section{DISCUSSION}

Data on PA, HRQoL and prevalence of MPS among students of different disciplines, especially Physiotherapy students, are limited. To the best of the authors' knowledge, this is the first study which to investigate and compare levels of PA, HRQoL, and the prevalence of MPS along with associations between them, among students of Physiotherapy and Social Sciences.

Adequate levels of physical activity are an essential part of a healthy lifestyle and prevention of disease and disability $[1,2,3,4]$, while prolonged sitting negatively affects health [5]. University students are of particular interest because they emerge into adulthood during university years and experience a number of stressors during this period [31]. One-third of the students who had been active in high school became insufficiently active once they started university, and those who became inactive reported higher levels of fatigue and lower levels of vigour, compared to their active peers [32].

Physiotherapists have an important role in promoting PA and their education makes them suitable for counseling about the importance, health-related benefits and the need to engage in PA. A recent study showed that physiotherapy students believe that they should serve as role models and practice a healthy lifestyle [33]. Physically active physicians and medical students are more likely to counsel their patients on the importance of PA $[34,35,36]$.

Level of physical activity. The reported level of PA in the presented sample was 3,759 MET-min/week, on average, which is the equivalent of approximately 134 minutes of moderate or 67 minutes of vigorous-intensity PA per day. Indeed, the majority of respondents exceeded the current WHO guidelines which recommend 150 minutes of moderate- or 75 minutes of vigorous-intensity aerobic activity per week [2]. The respondents exceeded even the level of PA needed to gain additional health benefits, which is at least 300 minutes of moderate-intensity or 150 minutes of vigorous-intensity PA per week [2]. Furthermore they accumulated higher levels of PA in comparison to the general Croatian population aged 15-24 years whose median of total PA was 42.7 MET-hours/week, e.g. 2562 MET-min/week [37].

A similar study has been performed on Polish Physiotherapy students. None of them had a low level of PA, 54\% demonstrated a moderate level of PA and $46 \%$ were categorized as highly physically active [38]. These results are somewhat different than those in the current study in which $10.6 \%$ of Physiotherapy students had a low level of PA, $28.1 \%$ reported a moderate level of PA, and a majority, $61.3 \%$, reported a high level of PA. This is similar to the results from a study performed on a sample of Austrian medical students where $10.7 \%$ reported a low level of PA, and $59.3 \%$ were classified as highly active [39].

A study performed on Egyptian students of different disciplines showed lower levels of PA than the presented sample. Their median of total PA was 2,256 MET-min/week. Furthermore, they reported a median of 0 MET-min/week of vigorous-intensity PA and $405 \mathrm{MET}$-min/week of moderateintensity PA [40]. Greek Health-Science students also reported lower levels of PA than the presented sample [41]. They reported that their median of vigorous-intensity PA was also $0 \mathrm{MET}-\mathrm{min} /$ week, and the medians for moderateintensity PA and total PA were 40 and 730 MET-min/week, respectively. When asked about their level of agreement with the statement "my level of PA is adequate", the most common answer for the total sample and the female subgroup was "neither agree nor disagree". However, on average, male respondents answered that they agreed with that statement. It was found that their answer positively correlated with their self-reported levels of PA. Thirty-eight percent of the Polish students of Physiotherapy claimed that they perceived themselves as physically active, but also reported that $98 \%$ of them had been physically active before they started university [38]. That, together with the findings of the current study, that they spent approximately 5 hours/day in a sitting position and most of them reporting that they neither agreed nor disagreed regarding the accumulation of an appropriate level of PA, to a greater extent suggests that there is a need to incorporate $\mathrm{PA}$ in the curriculum.

In general, male students were considerably more active than female, which was also confirmed for the general Croatian population [37]. Egyptian and Greek male students were also more physically active than female $[40,41]$. Likewise, the male population of Sweden aged 18-34 years is also more active than female [42]. Also, a large international study to assess PA participation in 20 countries revealed that males more frequently reported high PA than females in 17 of 20 countries [43].

Surprisingly, Social Sciences students accumulated higher levels of total PA, walking and vigorous-intensity PA, although the difference was insignificant. The authors of the presented study had to reject their first hypothesis. Still, Physiotherapy students accumulated higher levels of PA than the general population, which is in accordance with a similar study performed on American Physiotherapy students [15].

Health-Related Quality of Life. In comparison to the SF-36 national norms for adult men and women in Croatia aged 18-24 years [28], the presented sample scored lower in most domains: physical functioning, bodily pain, general health, vitality, social functioning and mental health. The median score was equal to the national norm in the domains of role functioning/physical and role functioning/emotional. Messina et al. [44] also reported lower SF-36 scores among Italian medical students in comparison to the general Italian population of the corresponding age group, as well as Henning et al. [45], in a study performed in New Zealand where university students reported lower levels of HRQoL compared to the general population.

Females had lower scores in the domains of general health, vitality and social functioning, while males had a lower score in the domain of mental health. Female nursing and 
medical students also scored lower in most SF-36 domains in comparison to male students [44, 46, 47]. A study performed on a general population of students at Belgrade University, Serbia, also reported lower SF-36 scores in most domains among female population [48]. This study compared students of different disciplines: social sciences and humanities, medical sciences, natural sciences and mathematics, and technology and engineering sciences. Significant differences have been found in the domains of vitality and mental health between students of social sciences and humanities and students of medical sciences which scored lower. In our study, Physiotherapy students scored higher in the domain of physical functioning and PCS, while Social Sciences students had a higher MCS score.

In the current study a significant positive but weak relationship was found between PA and 2 domains of SF36 , vitality and general health. Surprisingly, a weak negative relationship was also found between PA and the mental health domain. Time spent sitting was negatively related to vitality, social functioning, general health and MCS. A recent study [49] also found significant relationship between total PA and HRQoL and a negative relation between sitting time and mental health in a population of healthy male subjects between 20-40 years of age. Pedisic et al. [50] also reported a positive relationship between total PA and the domains of physical functioning, general health and vitality in female university students, and general health and vitality in male students. A study performed on a representative random sample of Croatian inhabitants revealed a significant relationship between PA and vitality, mental health, and MCS in female participants, and physical functioning, bodily pain, social functioning, mental health, and PCS in male participants [51]. In a sample of Iranian medical students, male gender and participation in daily PA were significantly associated with a higher PCS and MCS, which could not be confirm in the sample in the presented study [47].

Bize et al. [52], in their systematic review, described a strong positive association throughout cross-sectional studies between total PA and HRQoL in the general population of healthy adults. Higher total PA levels were associated with better HRQoL in various dimensions. Furthermore, high total sitting time and screen-viewing time were associated with a lower HRQoL, but high reading time predicted good mental and social health in middle-aged adults [53].

Musculoskeletal pain symptoms. A relatively high prevalence of MPS was recorded with $80.9 \%$ of students reporting pain symptoms during the past 12 months, and in $33.8 \%$ these symptomes prevented daily activities. Furthermore, MPS were negatively associated with several domains of SF-36, including PCS and MCS. A study performed on medical students in Saudi Arabia also found a high prevalence of MPS: $81.9 \%$ students reported MPS in the past year [54].

In the current study, the 12-month highest prevalence rates were in the lower back, the neck and upper back. Females reported a higher percentage of MPS and the most common body regions affected by MPS were the lower back, the neck and the upper back. Male students most commonly reported MPS in the lower back, the neck and knees. A study performed on allied health profession students in Jordan reported the highest prevalence of MPS in the neck, the lower back, shoulders, and upper back [20]. Similar to the current results where MPS in these areas were more prevalent in females, Jordanian female students were more likely to report a 12-month duration of MPS in the neck, shoulders, wrists and hands, the upper back, and hips/thighs. The highest prevalence of MPS which limited activities was due to lower back pain, followed by knee and upper back symptoms. Lower back MPS was also the most prevalent MPS causing difficulties in daily life activities among Jordanian allied health students, more in females than in males.

Healthcare workers have a high prevalence of MSD and more than half reported pain in the neck, the shoulder and lower back [55]. A study performed on occupational and physical therapists on work-related pain and discomfort prevalence reported similar prevalence among young healthcare workers (47\%) and older workers (43\%). The most common sites affected by MSD among younger workers were the lower back, the neck, and shoulders [56]. In the presented study, the highest prevalence of MPS in Physiotherapy students were in lower back and neck and the MPS in general were more prevalent among Physiotherapy students than Social Sciences students. Physiotherapy students in Jordan had the highest prevalence of MPS in the lower back, followed by the neck [20].

Lower levels of moderate-intensity and total PA were associated with a higher prevalence of MPS in the previous year. However, higher levels of vigorous-intensity and total PA were also associated with a higher prevalence of MPS which prevented daily activities. Exercise was not associated with any MPS in Jordanian or Saudi Arabia students [20, 54]. Furthermore, physical activity was not associated with lower back pain in Saudi Arabia university students of Medical and Health Sciences [57]. The presented study did not demonstrate a significant association between the time spent sitting and MPS. A study from Australia showed that exposure to tertiary education of a duration longer greater than 2 years was associated with lifetime, 12-month and one-month low back pain, along with spending more than 20 hours in the past month in a sitting position [19].

The second hypothesis of the authors of the current study was partially proven. Only weak evidence was found that those with higher levels of moderate-intensity PA had a lower prevalence of MPS, and higher scores in the domains of vitality and general health, while those with higher levels of vigorous-intensity PA had a higher prevalence of MPS preventing activities in the last year, but also higher scores in the domains of vitality and general health.

Strength and limitations of the study. The strength is the use of well-known, valid and reliable questionnaires which allowed comparison of the results obtained with the general population and student populations of different disciplines. This study is the first to investigate the levels of PA of different intensities among a subset of Eastern Croatian students of Physiotherapy and Social Sciences along with their HRQoL, the prevalence of MPS and relationships between them.

The main limitation is the possible over-reporting and under-reporting of PA, HRQoL and MPS. Although objective measurements of PA are more valid than self-report methods, IPAQ is a widely-accepted tool for the comparison of PA levels. Also, self-reported data of body height and body mass were used which could make the conclusions and analyses regarding BMI unreliable. Another limitation is the cross-sectional design of the study which did not permit causal relationships between PA, HRQoL and MPS. The relationship could be 
bidirectional. Also, there are significant seasonal variations in PA levels and the presented sample was surveyed during a narrow autumn period of the year, which might have resulted in a biased relationship with HRQoL. Furthermore, domainspecific physical activity and relationships between different domains of PA and HRQoL and MPS, were not assessed.

\section{CONCLUSIONS}

This study adds useful information to the body of evidence regarding university students' $\mathrm{PA}, \mathrm{HRQ}$ LL and MPS prevalence. The majority of students of both disciplines were highly physically active, but with a high prevalence of MPS, which could affect their HRQoL. Their perception of health is lower than in the general population, especially in the mental component which requires special attention. The presented sample scored lower than the national norms in most HRQoL domains. The relatively high prevalence of MPS could be related to that and should be addressed with preventive physical activity programmes. Due to gender differences in both PA levels and HRQoL, development of gender-specific preventive programmes is advisable. The results of the study could assist in the development of health promotion and intervention strategies aimed at students' health and lifestyle improvement.

\section{REFERENCES}

1. World Health Organization. Global health risks: mortality and burden of disease attributable to selected major risks, World Health Organization, 2009.

2. World Health Organization. Global recommendations on physical activity for health, World Health Organization, 2010.

3. Ekelund U, Steene-Johannessen J, Brown WJ, Fagerland MW, Owen N, Powell KE, et al. Does physical activity attenuate, or even eliminate, the detrimental association of sitting time with mortality? A harmonised meta-analysis of data from more than 1 million men and women. Lancet. 2016; 388(10051): 1302-1310.

4. 2018 Physical Activity Guidelines Advisory Committee. Physical Activity Guidelines Advisory Committee Scientific Report. U.S. Department of Health and Human Services, 2018.

5. Biswas A, Oh PI, Faulkner GE, Bajaj RR, Silver MA, Mitchell MS, et al. Sedentary time and its association with risk for disease incidence, mortality, and hospitalization in adults: a systematic review and metaanalysis. Ann Intern Med. 2015; 162(2): 123-132.

6. Caspersen CJ, Powell KE, Christenson GM. Physical activity, exercise, and physical fitness: definitions and distinctions for health-related research. Public Health Rep. 1985; 100(2): 126-131.

7. Tremblay MS, Aubert S, Barnes JD, Saunders TJ, Carson V, LatimerCheung AE, et al. Sedentary Behavior Research Network (SBRN) -Terminology Consensus Project process and outcome. Int J Behav Nutr Phys Act. 2017; 14(1): 75.

8. Revicki DA. Health-related quality of life in the evaluation of medical therapy for chronic illness. J Fam Pract. 1989; 29(4): 377-380.

9. Bize R, Johnson JA, Plotnikoff RC. Physical activity level and healthrelated quality of life in the general adult population: a systematic review. Prev Med. 2007; 45(6): 401-415.

10. Brown DW, Balluz LS, Heath GW, Moriarty DG, Ford ES, Giles WH, et al. Associations between recommended levels of physical activity and health-related quality of life. Findings from the 2001 Behavioral Risk Factor Surveillance System (BRFSS) survey. Prev Med. 2003; 37(5): 520-528.

11. Brown DW, Brown DR, Heath GW, Balluz L, Giles WH, Ford ES, et al. Associations between physical activity dose and health-related quality of life. Med Sci Sports Exerc. 2004; 36(5): 890-896.

12. Vuillemin A, Boini S, Bertrais S, Tessier S, Oppert JM, Hercberg S, et al. Leisure time physical activity and health-related quality of life. Prev Med. 2004; 41(2): 562-569.
13. World Health Organization. Global action plan on physical activity 2018-2030: more active people for a healthier world. World Health Organization, 2018.

14. Milošević M, Golubić R, Mustajbegović J, Doko Jelinić J, Janev Holcer N, et al. Regional pattern of physical inactivity in Croatia. Coll Antropol. 2009; 33(Suppl 1): 35-38.

15. Chevan J, Haskvitz EM. Do as I do: exercise habits of physical therapists, physical therapist assistants, and student physical therapists. Phys Ther. 2010; 90(5): 726-734.

16. Barbosa RE, Assuncão AA, de Araújo TM. Musculoskeletal pain among healthcare workers: an exploratory study on gender differences. Am J Ind Med. 2013; 56(10): 1201-1212.

17. da Costa BR, Vieira ER. Risk factors for work-related musculoskeletal disorders: a systematic review of recent longitudinal studies. Am J Ind Med. 2010; 53(3): 285-323.

18. Hanvold TN, Veiersted KB, Waersted M. A prospective study of neck, shoulder, and upper back pain among technical school students entering working life. J Adolesc Health. 2010; 46(5): 488-494.

19. Nyland LJ, Grimmer KA. Is undergraduate physiotherapy study a risk factor for low back pain? A prevalence study of LBP in physiotherapy students. BMC Musculoskelet Disord. 2003; 4: 22.

20. Almhdawi KA, Mathiowetz V, Al-Hourani Z, Khader Y, Kanaan SF, Alhasan M. Musculoskeletal pain symptoms among allied health professions' students: prevalence rates and associated factors. J Back Musculoskeletal Rehabil. 2017; 30(6): 1291-1301.

21. Guddal MH, Stensland S $\varnothing$, Småstuen MC, Johnsen MB, Zwart JA, Storheim K. Physical activity level and sport participation in relation to musculoskeletal pain in a population-based stuedy of adolescents: The Young-HUNT study. Orthop J Sports Med. 2017; 5(1): 2325967116685543.

22. Paananen M, Taimela S, Auvinen J, Tammelin T, Zitting P, Karppinen J. Impact of self-reported musculoskeletal pain on health-related quality of life among young adults. Pain Med. 2011; 12(1): 9-17.

23. Craig CL, Marshall AL, Sjöström M, Bauman AE, Booth ML, Ainsworth $\mathrm{BE}$, et al. International physical activity questionnaire: 12-country reliability and validity. Med Sci Sports. 2003; 35(8): 1381-1395.

24. IPAQ Group. Guidelines for the data processing and analysis of the International Physical Activity Questionnaire: short and long forms. https://sites.google.com/site/theipaq/scoring-protocol (access: 2018.07.16).

25. Ware JE, Sherbourne CD. The MOS 36-item short-form health survey (SF-36). I. Conceptual framework and item selection. Med Care. 1992; 30(6): 473-483.

26. Ware JE, Snow KK, Kosinski M, Gandek B. The SF-36 Health Survey manual and interpretation guide. New England Medical Center, The Health Institute, 1993.

27. Jureša V, Ivanković D, Vuletić G, Babić-Banaszak A, Srcek I, Mastilica M, et al. The Croatian Health Survey - SF-36: I. General quality of life assessment. Coll Antropol. 2000; 24(1): 69-78.

28. Maslić Seršić D, Vuletić G. Psychometric evaluation and establishing norms of Croatian SF-36 Health Survey: framework for subjective health research. Croat Med J. 2006; 47(1): 95-102.

29. Ware JE, Kosinski M, Keller SD. SF-36 Physical and Mental Health Summary Scales - A User's Manual. New England Medical Center, The Health Institute, 1994.

30. Kourinka I, Jonsson B, Kilborn A, Vinterberg H, Biering-Sørensen F, Andersson G, et al. Standardised Nordic questionnaires for the analysis of musculoskeletal symptoms. Appl Ergon. 1987; 18(3): 233-237.

31. Joseph RP, Royse KE, Benitez TJ, Pekmezi DW. Physical activity and quality of life among university students: exploring self-efficacy, selfesteem, and affect as potential mediators. Qual Life Res. 2014; 23(2): $659-667$.

32. Bray SR, Born HA. Transition to university and vigorous physical activity: implications for health and psychological well-being. J Am Coll Health. 2004; 52(4): 181-188.

33. Black B, Marcoux BC, Stiller C, Qu X, Gellish R. Personal health behaviors and role-modeling attitudes of physical therapists and physical therapist students: a cross-sectional study. Phys Ther. 2012; 92(11): 1419-1436.

34. Abramson S, Stein J, Schaufele M, Frates E, Rogan S. Personal exercise habits and counseling practices of primary care physicians: a national survey. Clin J Sport Med. 2000; 10(1): 40-48.

35. Frank E, Carrera JS, Elon L, Hertzberg VS. Predictors of US medical students' prevention conseling practices. Prev Med. 2007; 44(1): 76-81.

36. Frank E, Bhat Schelbert K, Elon L. Exercise counseling and personal exercise habits of US women physicians. J Am Med Womens Assoc (1972). 2003; 58(3): 178-184. 
37. Jurakić D, Pedišić Z, Andrijašević M. Physical activity of Croatian population: Cross-sectional study using International Physical Activity Questionnaire. Croat Med J. 2009; 50(2): 165-173.

38. Dabrowska-Galas M, Plinta R, Dabrowska J, Skrzypulec-Plinta V. Physical activity in students of the Medical University of Silesia in Poland. Phys Ther. 2013; 93(3): 384-392.

39. Lackinger C, Dorner TE. Achievement of physical activity recommendation and activity levels in students of human medicine compared with the general Austrian population aged between 20 and 29 years. Wien Med Wochenschr. 2015; 165(5-6): 116-123.

40. El-Gilany AH, Badawi K, El-Khawaga G, Awadalla N. Physical activity profile of students in Mansoura University, Egypt. East Mediterr Health J. 2011; 17(8): 694-702.

41. Papathanasiou G, Papandreou M, Galannos A, Kortianou E, Tsepis E, Kalfakakou V, et al. Smoking and physical activity interrelations in health science students. Is smoking associated with physical inactivity in young adults? Hellenic J Cardiol. 2012; 53(1): 17-25.

42. Hagströmer M, Bergman P, Bauman A, Sjöström. The International Prevalence Study (IPS): health-enhancing physical activity in Sweden. J Public Health. 2006; 14(5): 301-308.

43. Bauman A, Bull F, Chey T, Craig CL, Ainsworth BE, Sallis JF, et al. The International Prevalence Study of physical activity: results from 20 countries. Int J Behav Nutr Phys Act. 2009; 6: 21.

44. Messina G, Quercioli C, Troiano G, Russo C, Barbini E, Nisticò F, et al. Italian medical students quality of life: years 2005-2015. Ann Ig. 2016; 28(4): 245-251.

45. Henning MA, Krägeloh CU, Hawken SJ, Zhao Y, Doherty I. The quality of life of medical students studying in New Zealand: a comparison with nonmedical students and a general population reference group. Teach Learn Med. 2012; 24(4): 334-340.

46. Souza IM, Paro HB, Morales RR, Pinto Rde M, da Silva CH. Healthrelated quality of life and depressive symptoms in undegraduate nursing students. Rev Lat Am Enfermagem. 2012; 20(4): 736-743.

47. Jamali A, Tofangchiha S, Jamali R, Nedjat S, Jan D, Narimani A, et al. Medical student's health-related quality of life: roles of social and behavioural factors. Med Educ. 2013; 47(10): 1001-1012.
48. Pekmezović T, Popović A, Tepavčević DK, Gazibara T, Paunić M. Factors associated with health-related quality of life among Belgrade University students. Qual Life Res. 2011; 20(3): 391-397.

49. Päivärinne V, Kautiainen H, Heinonen A, Kiviranta I. Relations beteween subdomains of physical activity, sedentary lifestyle, and quality of life in young adult men. Scand J Med Sci Sports. 2018; 28(4): 1389-1396.

50. Pedišić Z, Rakovac M, Titze S, Jurakić, Oja P. Domain-specific physical activity and health-related quality of life in university students. Eur J Sport Sci. 2014; 14(5): 492-499.

51. Jurakić D, Pedišić Z, Greblo Z. Physical activity in different domains and health-related quality of life: a population-based study. Qual Life Res. 2010; 19(9): 1303-1309.

52. Bize R, Johnson JA, Plotnikoff RC. Physical activity level and healthrelated quality of life in the general adult population: a systematic review. Prev Med. 2007; 45(6): 401-415.

53. Omorou AY, Vuillemin A, Menai M, Latarche C, Kesse-Guyot E, Galan $\mathrm{P}$, et al. 10-year cumulative and bidirectional associations of domainspecific physical activity and sedentary behaviour with health-related quality of life in French adults: Results from the SU.VI.MAX studies. Prev Med. 2016; 88: 66-72.

54. Algarni AD, Al-Saran Y, Al-Moawi A, Bin Dous A, Al-Ahaideb A, Kachanathu SJ. The prevalence of and factors associated with neck, shoulder, and low-back pains among medical students at University Hospitals in Central Saudi Arabia. Pain Res Treat. 2017; 2017:1235706.

55. Zhang X, Zheng Y, Wang R. Effect of musculoskeletal disorders on the occupational activity and health of health professional. Wei Sheng Yan Jiu. 2007; 36(3): 333-335.

56. King P, Huddleston W, Darragh AR. Work-related musculoskeletal disorders and injuries: Differences among older and younger occupational and physical therapists. J Occupl Rehabil. 2009; 19(3): 274-283.

57. AlShayhan FA, Saadeddin M. Prevalence of low back pain among health sciences students. Eur J Orthop Surg Traumatol. 2018; 28(2): 165-170. 